\title{
Rheological Evaluation of Carbon Nanotube Redistribution in Polymer Melt
}

\author{
Riho Nishikawa, Howon Yoon, Masayuki Yamaguchi ${ }^{\dagger}$ \\ School of Materials Science, Japan Advanced Institute of Science and Technology, \\ 1-1 Asahidai, Nomi, Ishikawa, 923-1292, Japan
}

(Received : March 29, 2019)

\begin{abstract}
We investigated changes to the linear viscoelastic properties of a mixture comprising polycarbonate (PC) containing 3 wt. $\%$ of a multiwalled carbon nanotube (MWCNT) and high-density polyethylene (HDPE), also containing 3 wt. $\%$ MWCNT, during post-processing annealing. The oscillatory shear moduli - i.e., the storage modulus $G^{\prime}$ and the loss modulus $G^{\prime \prime}$ - gradually increased with residence time in a rheometer (i.e., annealing). The samples were prepared by compression-molding at low temperature, during which the MWCNTs became oriented by the applied squeeze flow. The marked increase in the oscillatory moduli may be attributed to the formation of a conductive MWCNT network owing to Brownian motion. Furthermore, the moduli increased more rapidly during high-temperature annealing. These increases can be expressed by a simple equation using only one characteristic time, i.e., the time required for MWCNT redistribution by Brownian motion. This characteristic time is considered one of the factors that control the structure of composites containing MWCNTs.
\end{abstract}

Keywords: Nanoparticles / Viscoelastic properties / Networks / Composites

\section{INTRODUCTION}

Various polymer properties may be greatly modified by the addition of a small amount of nanofiller. The materials obtained by such an approach are often referred to as nanocomposites. One of the most significant ways in which such materials differ from conventional composites is in the occurrence of Brownian motion, which can be detected in a polymer melt. Consequently, the dispersion of nanofillers in a polymer can be modified by the post-processing annealing procedure. This behavior has been studied in detail, both theoretically $^{1)}$ and experimentally ${ }^{2-8)}$. Because Brownian motion affects filler distribution, it must be understood in detail to ensure the appropriate morphology of the polymer nanocomposite. With regard to the compression-molding process, it is also important to predict the residence time and the temperature in the mold to ensure the homogeneous distribution of the nanofiller in the polymer melt by Brownian motion.

The effect of Brownian motion on the rheological response in a concentrated suspension has been studied intensively by Shikata et $a l^{3,5,6)}$, who used hard-sphere particles. They found that such a system is weakly elastic owing to

\footnotetext{
$\dagger$ Corresponding author.

E-mail : m yama@jaist.ac.jp

Tel: +81-761-51-1621; Fax: +81-761-51-1149
}

Brownian motion, which is provided by the redistribution of particles from a shear-distorted dispersion state to an equilibrium state. Furthermore, rigid particles in condensed systems sometimes hardly move with respect to each other owing to intense interparticle interactions such as frictional force. Therefore, such systems require a considerable time for redistribution, which results in a solid-like mechanical behavior.

Following their discovery by Iijima ${ }^{9}$, carbon nanotubes (CNTs) have become one of the best-known functional nanofillers because they provide an electrical and/or thermal conductive path, even when present in small amounts. Pötschke et al. reported that the storage and loss moduli increase significantly - especially in the low frequency region - with increasing content of multiwalled carbon nanotubes (MWCNTs) in composites comprising polycarbonate (PC) and MWCNTs ${ }^{10-12)}$. According to those researchers, the increase in the oscillatory moduli may be attributed to the formation of a network structure composed of MWCNTs; this network structure provides good electrical conductivity ${ }^{13,14)}$. As is well known, polymer composites containing electroconductive fillers can be transformed from electrical insulators to conductors by increasing the filler content. The percolation threshold of conductive fillers decreases with their aspect ratio ${ }^{15-21)}$. Therefore, a small number of MWCNTs is 
sufficient to confer conductivity when they are homogeneously distributed in a polymer. The percolation threshold of MWCNTs is approximately 1-3 wt.\% for mechanically blended samples composed of PC and MWCNTs ${ }^{22)}$. However, because they are expensive, there is a strong incentive to reduce the number of MWCNTs in the composition. As mentioned previously, a network structure composed of MWCNTs can be obtained by Brownian motion, i.e., redistribution to an equilibrium state.

In the present study, we studied the dispersion of MWCNTs in a molten PC and high-density polyethylene (HDPE) using a rheological approach with the electrical conductivity as a function of the post-processing annealing procedure. We found that the development of a network structure can be expressed by a simple formula.

\section{EXPERIMENTAL}

\subsection{Materials}

The polymers used in the present research were bisphenol-A polycarbonate (PC) (Panlite L-1225Y; Teijin, Ltd., Japan) (melt flow rate $(\mathrm{MFR})=11 \mathrm{~g} / 10 \mathrm{~min}$ ) and high-density polyethylene (HDPE) (HJ590N; Japan Polyethylene Corp., Japan) $(\mathrm{MFR}=40 \mathrm{~g} / 10 \mathrm{~min})$. The number- and weightaverage molecular weights, characterized by size exclusion chromatography (SEC) (HLC-8020, Tosoh Corp., Japan) using chloroform as an eluent, were $M_{n}=1.9 \times 10^{4}$ and $M_{w}=9.7 \times 10^{4}$ for PC using polystyrene as a standard. The $M_{n}$ and $M_{w}$ of HDPE were also characterized by SEC using 1,2,4-trichlorobenzene at $140^{\circ} \mathrm{C}$, and were found to be $M_{n}=8.7 \times 10^{3}$ and $M_{w}=4.9 \times 10^{4}$, respectively, using polyethylene as a standard. The densities of the PC and HDPE at $23{ }^{\circ} \mathrm{C}$ were $1200 \mathrm{~kg} / \mathrm{m}^{3}$ and $960 \mathrm{~kg} / \mathrm{m}^{3}$, respectively. A composite of PC with $20 \mathrm{wt} . \%$ of MWCNT and another composite of HDPE with 3 wt.\% of MWCNT were provided by Hodogaya Chemical Co., Ltd. (Japan) in pellet form. The MWCNT had a diameter of 40-80 nm, and was between 10 and $20 \mu \mathrm{m}$ long. The density of the MWCNTs was $2300 \mathrm{~kg} / \mathrm{m}^{3}$.

\subsection{Preparation of composites}

We dried the PC and the masterbatch for approximately $5 \mathrm{~h}$ at $120^{\circ} \mathrm{C}$ in a vacuum oven. The masterbatch containing 20 wt.\% of MWCNTs was diluted with the pure molten PC using a $30 \mathrm{cc}$ internal batch-type mixer with kneading disks (IMC-1891; Imoto Co., Ltd., Japan) at $280^{\circ} \mathrm{C}$ for $5 \mathrm{~min}$. The blade rotation speed was $50 \mathrm{rpm}$. The obtained PC composite and the HDPE composite containing $3 \mathrm{wt} . \%$ of MWCNTs were compressed into flat, ca. 1.2-mm-thick sheets using a compression-molding machine (Table-type testpress; Tester Sangyo Co., Ltd., Japan). The mold temperature was controlled at either 200 or $300{ }^{\circ} \mathrm{C}$ for $\mathrm{PC}$, and either 150 or $300{ }^{\circ} \mathrm{C}$ for HDPE, under an applied pressure of $10 \mathrm{MPa}$. The residence time in the mold was $3 \mathrm{~min}$. We obtained the sheets after quenching with cold water at $25-30^{\circ} \mathrm{C}$.

\subsection{Measurements}

We obtained growth curves of the oscillatory shear moduli at a constant angular frequency of $1.0 \mathrm{rad} / \mathrm{s}$ using a strain-controlled parallel-plate rheometer (MR-500; UBM, Japan) under a nitrogen atmosphere at either 250 or $300{ }^{\circ} \mathrm{C}$ for $\mathrm{PC}$, and 150 or $250{ }^{\circ} \mathrm{C}$ for HDPE. The diameter of the plate was $25 \mathrm{~mm}$ and the gap between the plates was approximately $1 \mathrm{~mm}$. The strain amplitude was selected to be within the linear viscoelastic range.

To evaluate the degree of thermal degradation of PC during the rheological measurements, the molecular weights of the PCs in the composites were measured by size exclusion chromatography (SEC) (HLC-8020; Tosoh Corp., Japan) with TSK-GEL1 GMHXL; chloroform was used as the eluant at a flow rate of $1.0 \mathrm{ml} / \mathrm{min}$. The temperature was maintained at $40{ }^{\circ} \mathrm{C}$ and the sample concentration was $1.0 \mathrm{mg} / \mathrm{ml}$. Prior to the measurement, we carried out filtration treatment using a filter with $0.45-\mu \mathrm{m}$ pores to remove the MWCNTs.

We examined the morphology of the blends using a scanning electron microscope (SEM) (S4100; Hitachi, Ltd., Japan). Prior to examination, we sputter-coated the surfaces of the cryogenically fractured samples with $\mathrm{OsO}_{4}$.

We measured surface and volume resistivities using a constant voltage-supplied resistivity meter (MCP-T610; Mitsubishi Chemical Analytech Co., Ltd., Japan). The measurements were performed nine times for each sample at $23{ }^{\circ} \mathrm{C}$, and the average values were calculated.

\section{RESULTS AND DISCUSSION}

Figure 1 shows the angular frequency dependence of the shear moduli - i.e., the storage modulus $G^{\prime}$ and the loss modulus $G^{\prime \prime}$ - of PC/MWCNT (3 wt.\%) and HDPE/ MWCNT (3 wt.\%) at $250^{\circ} \mathrm{C}$. Both samples were prepared by compression-molding at $300{ }^{\circ} \mathrm{C}$. It is obvious that the plateau moduli appear in the low frequency region, suggesting the presence of a network structure. In other words, there was interparticle interaction between neighbor MWCNTs in the molten PC and HDPE, which dominated the viscoelastic properties in the low frequency region. 

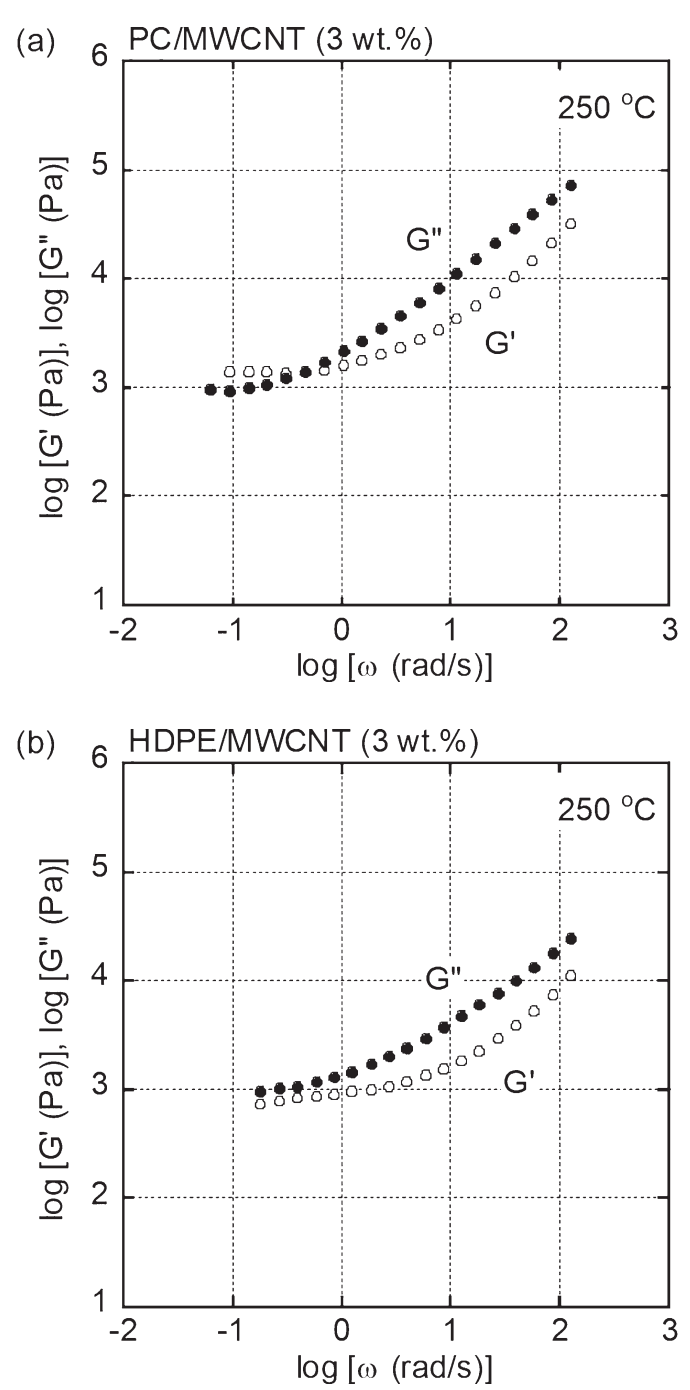

Fig. 1 Angular frequency dependence of shear moduli - i.e., the storage modulus $G^{\prime}$ (open circles) and the loss modulus $G^{\prime \prime}$ (closed circles) at $250^{\circ} \mathrm{C}$ of (a) PC/MWCNT (3 wt.\%) and (b) HDPE/MWCNT (3 wt.\%). $\mathrm{PC}=$ polycarbonate; $\quad \mathrm{MWCNT}=$ multi-walled $\quad$ carbon nanotube; $\mathrm{HDPE}=$ high-density polyethylene.

The growth curves of the oscillatory shear moduli i.e., the storage modulus $G^{\prime}$ and the loss modulus $G^{\prime \prime}$ - at $250{ }^{\circ} \mathrm{C}$ and $300^{\circ} \mathrm{C}$ for PC/MWCNT (3 wt.\%) obtained by compression-molding at $200{ }^{\circ} \mathrm{C}$ are shown in Fig. 2. The values of $G^{\prime}$ and $G^{\prime \prime}$ gradually increased with the residence time in the rheometer, i.e., the annealing period $\tau_{a}$. Furthermore, we confirmed that it takes a longer time to be constant values of both moduli at the low temperature $\left(250^{\circ} \mathrm{C}\right)$. The measurements provided the experimental error in the short time region, because it took some periods to control the temperature (it took longer time to be at $300{ }^{\circ} \mathrm{C}$, leading to a rapid increase in $G^{\prime}$ in the short time region).

The degree of thermal degradation of PC during the rheological measurements was evaluated using the SEC measurements. We found that the molecular weight and molecular weight distribution of the sample annealed at $300{ }^{\circ} \mathrm{C}$ were the same as those of the sample annealed at $200{ }^{\circ} \mathrm{C}$ (Fig. 3).
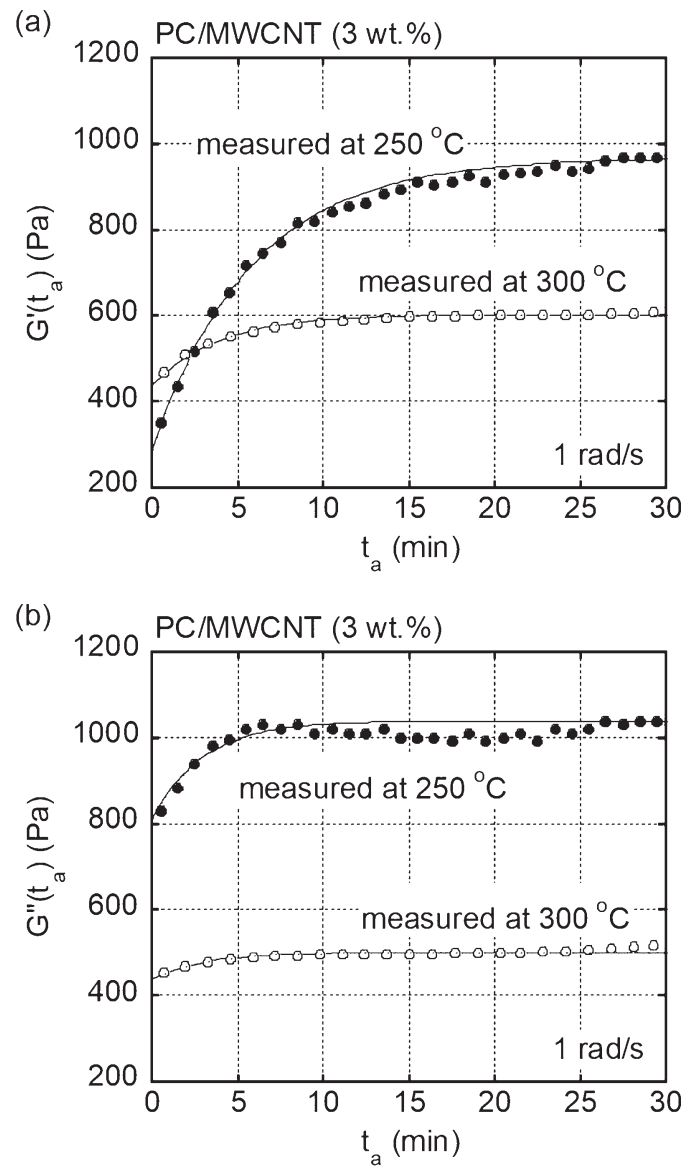

Fig. 2 Growth curves of (a) shear storage modulus $G^{\prime}$ and (b) shear loss modulus $G^{\prime \prime}$ at $250{ }^{\circ} \mathrm{C}$ (closed circles) and $300^{\circ} \mathrm{C}$ (open circles) for PC/MWCNT (3 wt.\%) compressed at $200{ }^{\circ} \mathrm{C}$. The angular frequency was $1.0 \mathrm{rad} / \mathrm{s}$. The values of the solid lines were calculated using eq. (1). $\mathrm{PC}=$ polycarbonate; $\mathrm{MWCNT}=$ multi-walled carbon nanotube.

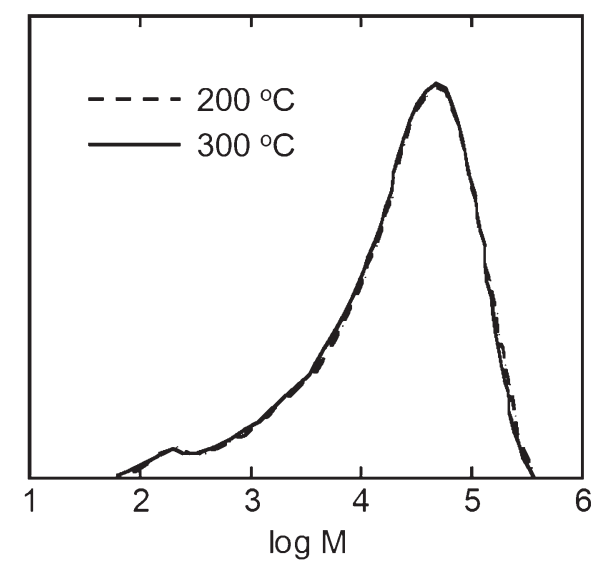

Fig. 3 GPC curves of PC/MWCNT (3wt.\%) annealed at $200{ }^{\circ} \mathrm{C}$ and $300{ }^{\circ} \mathrm{C}$. $\mathrm{GPC}=$ gel permeation chromatography; $\mathrm{PC}=$ polycarbonate; $\mathrm{MWCNT}=$ multi-walled carbon nanotube.

These results demonstrate that the modulus increase may be attributed to the formation of an MWCNT network. In other words, the applied squeeze flow during compression-molding orients the MWCNTs, as revealed by our previous study ${ }^{22)}$, and is responsible for the decrease in the interparticle interaction between neighboring MWCNTs. Subsequently, Brownian motion during annealing in the 
rheometer leads to random orientation and results in the formation of an MWCNT network.

It should be noted that we did not detect a modulus change in the rheometer for the composite sample compressed at $300{ }^{\circ} \mathrm{C}$, demonstrating that the MWCNT distribution was in equilibrium during compression-molding, i.e., $300{ }^{\circ} \mathrm{C}$ for $3 \mathrm{~min}$.

The growth curves of $G^{\prime}$ and $G^{\prime \prime}$ in Fig. 2 can be described by the following simple equation, as shown by the solid lines in the figure:

$$
G\left(t_{a}\right)=G_{i}+\left(G_{e q}-G_{i}\right)\left[1-\exp \left(-\frac{t_{a}}{\tau_{a}}\right)\right]
$$

where $G_{i}$ and $G_{e q}$ are the storage or loss moduli at the initial $\left(t_{a}=0\right)$ and equilibrium $\left(t_{a}=\infty\right)$ conditions at the same frequency, respectively. A similar equation was proposed to express the recovery curve of oscillatory moduli from the shear modification of low-density polyethylene ${ }^{23,24)}$.

In eq. (1), $\left(G_{e q}-G_{i}\right)$, which expresses the deviation in the modulus from the equilibrium state, should be determined by the applied flow condition. Therefore, the contribution made by Brownian motion can be expressed by only one parameter, i.e., $\tau_{a}$. This is the characteristic time of the orientation relaxation during annealing. In other words, the orientation relaxation of MWCNTs is a simple relaxation process with one characteristic time. Furthermore, the value of $\tau_{a}$ measured at $250{ }^{\circ} \mathrm{C}(348 \mathrm{~s})$ was longer than that at $300{ }^{\circ} \mathrm{C}$ (234 s). This was as expected because the relaxation time at $300{ }^{\circ} \mathrm{C}$ was shorter than that at $250^{\circ} \mathrm{C}$.

Figure 4 shows the growth curves of the shear moduli - i.e. the storage modulus $G^{\prime}$ and the loss modulus $G^{\prime \prime}$ at 150 and $250{ }^{\circ} \mathrm{C}$ for HDPE/MWCNT (3 wt.\%) obtained by compression-molding at $150{ }^{\circ} \mathrm{C}$. Similar to PC/MWCNT (3 wt.\%), the values of $G^{\prime}$ and $G^{\prime \prime}$ gradually increased with increasing residence time in the rheometer. This behavior is also expressed by eq. (1) with only one characteristic time, which is shown by the solid lines in the figure. Both moduli at the low temperature $\left(150^{\circ} \mathrm{C}\right)$ exhibited a marked increase over a wide range of annealing times compared with the moduli at the high temperature $\left(250^{\circ} \mathrm{C}\right)$. The value of $\tau_{a}$ measured at $150{ }^{\circ} \mathrm{C}(690 \mathrm{~s})$ was longer than that at $250{ }^{\circ} \mathrm{C}(450 \mathrm{~s})$, as expected.

Moreover, we found that the temperature dependence of $\tau_{a}$ in the HDPE system was less marked than that in the PC system. This may be attributed to the difference in the flow activation energy between PC (ca. $50 \mathrm{~kJ} / \mathrm{mol}$ ) and HDPE (ca. $24 \mathrm{~kJ} / \mathrm{mol})^{25,26)}$. Because Brownian motion is affected by the zero-shear viscosity of the medium, i.e., the matrix, the low
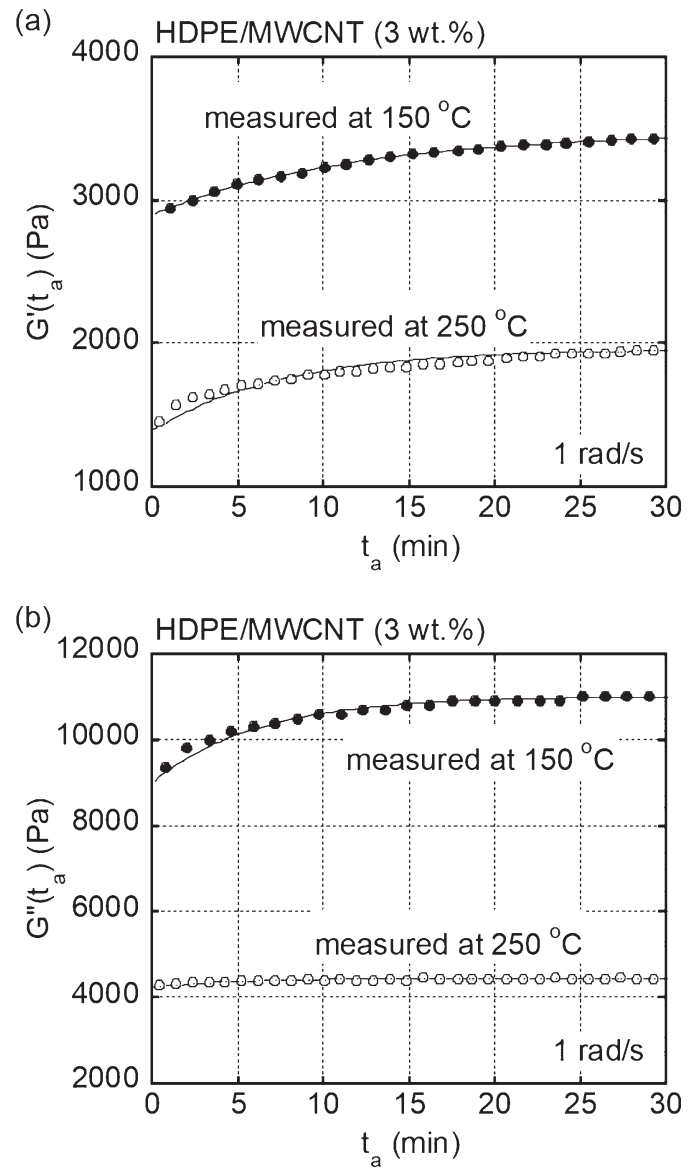

Fig. 4 Growth curves of (a) shear storage modulus $G^{\prime}$ and (b) shear loss modulus $G^{\prime \prime}$ at $150{ }^{\circ} \mathrm{C}$ (closed circles) and $250^{\circ} \mathrm{C}$ (open circles) for HDPE/MWCNT (3 wt.\%) compressed at $150^{\circ} \mathrm{C}$. The angular frequency was $1.0 \mathrm{rad} / \mathrm{s}$. The values of the solid lines were calculated using eq. (1). HDPE = high-density polyethylene; $\mathrm{MWCNT}=$ multiwalled carbon nanotube.

value of the flow activation energy for HDPE was responsible for the weak dependence of the ambient temperature.

To clarify the effect of annealing temperature on the dispersion of MWCNTs, we used SEM to examine the fractured surfaces of the HDPE/MWCNT (3 wt.\%) composites compressed at 150 and $300^{\circ} \mathrm{C}$. As shown in Fig. 5, the MWCNTs in the HDPE compressed at the low temperature $\left(150{ }^{\circ} \mathrm{C}\right)$ aligned parallel to the flow direction, i.e., perpendicular to the compression direction. In contrast, the MWCNTs in the HDPE compressed at the high temperature $\left(300{ }^{\circ} \mathrm{C}\right)$ oriented randomly. We detected similar phenomena in previous studies ${ }^{14,27)}$. These results suggest that the structural development of the PC/MWCNT and HDPE/MWCNT composites during the annealing procedure is attributed to the rotational diffusion of the MWCNTs in the molten PC and HDPE, owing to Brownian motion. Similar results were reported previously ${ }^{13,22,28,29)}$.

The redistribution of conductive MWCNTs in a polymer melt provides the conductive network. In other words, the electrical conductivity of the composites can be greatly 


\section{(a) HDPE/MWCNT compressed at $150{ }^{\circ} \mathrm{C}$}

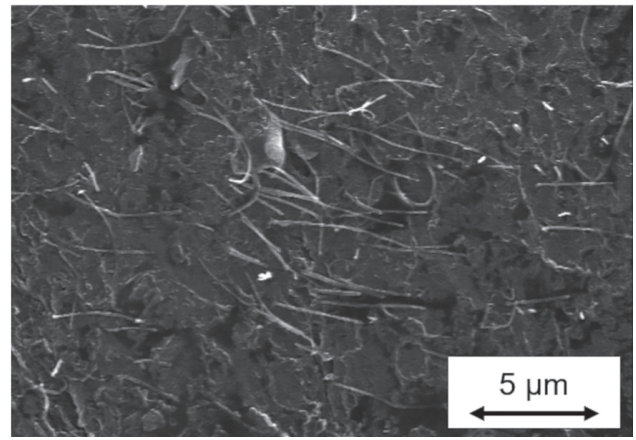

(b) HDPE/MWCNT compressed at $300^{\circ} \mathrm{C}$

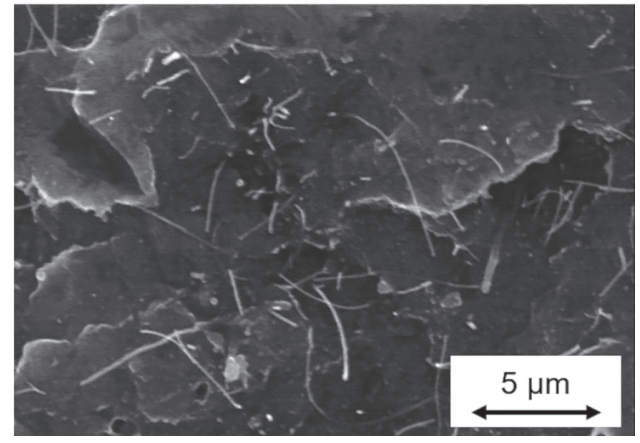

Fig. 5 Distribution of MWCNTs in HDPE at the cut surface of the compressed sheets of (a) HDPE/MWCNT (3 wt.\%) at $150{ }^{\circ} \mathrm{C}$ and (b) HDPE/MWCNT ( 3 wt.\%) at $300{ }^{\circ} \mathrm{C}$. The compressive deformation was applied in the normal direction in the pictures. HDPE = high-density polyethylene; MWCNT = multi-walled carbon nanotube.

Table I Surface and volume resistivity values of HDPE/MWCNT (3 wt.\%) compression-molded at $150^{\circ} \mathrm{C}$ and $300^{\circ} \mathrm{C}$.

\begin{tabular}{|c|c|c|}
\hline $\begin{array}{c}\text { Temperature at } \\
\text { compression-molding } \\
\left({ }^{\circ} \mathrm{C}\right)\end{array}$ & $\begin{array}{c}\text { Surface resistivity } \\
(\Omega / \text { sq. })\end{array}$ & $\begin{array}{c}\text { Volume resistivity } \\
(\Omega \cdot \mathrm{cm})\end{array}$ \\
\hline 150 & $2.2 \times 10^{3}$ & $1.6 \times 10^{2}$ \\
\hline 300 & $9.4 \times 10^{1}$ & 7.9 \\
\hline
\end{tabular}

HDPE $=$ high-density polyethylene; MWCNT $=$ multi-walled carbon nanotube

improved by choosing appropriate processing conditions and/or post-processing annealing conditions, such as the applied thermal and flow history.

We measured the electrical conductivity of the composites at room temperature using HDPE/MWCNT (3 wt.\%) sheets compressed at 150 and $300^{\circ} \mathrm{C}$. Table I shows the surface and volume resistivity values of the samples. The sample prepared by compression-molding at $300{ }^{\circ} \mathrm{C}$ had low resistivity values, which may be attributed to the formation of a network of MWCNTs.

\section{CONCLUSIONS}

We studied the rheological properties of a compression-molded plate containing MWCNTs oriented by the applied squeeze flow during post-processing annealing. The oscillatory moduli - i.e., the storage modulus $G^{\prime}$ and the loss modulus $G^{\prime \prime}$ - of the sample prepared at low temperature were lower than those prepared at high temperature owing to the orientation of the MWCNTs. Moreover, the moduli increased with increasing post-processing annealing time in the rheometer, owing to Brownian motion, which resulted in the interparticle interaction of the MWCNTs and thus the formation of an MWCNT network. These structural developments can be expressed by a simple equation using only one characteristic time, i.e., the time required for MWCNT redistribution by Brownian motion. This characteristic time is considered one of the factors that control the structure of composites containing MWCNTs during annealing.

\section{ACKNOWLEDGMENTS}

A part of this work was supported by JSPS Grant-in-Aid for Scientific Research (B) Grant Number 16H04201.

\section{NOMENCLATURE LIST}

$G\left(t_{a}\right)=$ the storage or loss moduli at the annealing time $\left(t_{a}\right)$ [Pa]

$G_{i}=$ the storage or loss moduli at the initial $\left(t_{a}=0\right)$ conditions at the same frequency $[\mathrm{Pa}]$

$G_{e q}=$ the storage or loss moduli at the equilibrium $\left(t_{a}=\infty\right)$ conditions at the same frequency $[\mathrm{Pa}]$

$t_{a}=$ annealing time [min]

$\tau_{a}=$ the characteristic time of the orientation relaxation during annealing [min]

\section{REFERENCES}

1) Doi M, Edwards SF, "The theory of polymer dynamics", (1986), Oxford University Press, Oxford.

2) Krieger IM, Adv Colloid Interface Sci, 3, 111 (1972).

3) Shikata T, Pearson DS, J Rheol, 38, 601 (1994).

4) Brady JF, Curr Opin Colloid Interface Sci, 1, 472 (1996).

5) Shikata T, Niwa H, Morishima Y, J Rheol, 42, 765 (1998).

6) Watanabe $\mathrm{H}$ et al., Rheol Acta, 38, 2 (1999).

7) Igarashi K et al., J Appl Phys, 115, 203506 (2014).

8) Konno T, Norisuye T, Sugita K, Nakanishi H, Tran-Cong Miyata Q, Ultrasonics, 65, 59 (2016).

9) Iijama S, Nature, 354, 56 (1991).

10) Pötschke P, Fornes TD, Paul DR, Polymer, 43, 3247 (2002).

11) Pötschke P, Abdel-Goad M, Alig I, Dudkin S, Lellinger D, Polymer, 45, 8863 (2004).

12) Abdel-Goad M, Pötschke P, J Non-newton Fluid Mech, 128, 2 (2005). 
13) Yoon H, Okamoto K, Yamaguchi M, Carbon, 47, 2840 (2009).

14) Wiwattananukul R, Fan B, Yamaguchi M, Compos Sci Technol, 141, 106 (2017).

15) Kirkpatrick S, Rev Mod Phys, 45, 574 (1973).

16) Pike GE, Seager CH, Phys Rev B, 10, 1421 (1974).

17) Balberg I, Binenbaum N, Phys Rev B, 28, 3799 (1983).

18) Celzard A, et al., Phys Rev B, 53, 6209 (1996).

19) Barrau S, Demont P, Peigney A, Laurent C, Lacabanne C, Macromolecules, 36, 5187 (2003).

20) Du F et al., Macromolecules, 37, 9048 (2004).

21) Natsuki T, Endo M, Takahashi T, Physica A, 352, 498 (2005).

22) Yoon H, Okamoto K, Umishita K, Yamaguchi M, Polym Compos, 32, 97 (2011).
23) Yamaguchi M, Gogos CG, Adv Polym Technol, 20, 261 (2001).

24) Yamaguchi M, J Appl Polym Sci, 102, 1078 (2006).

25) Vega JF, Santamaría A, Muñoz-Escalona A, Lafuente P, Macromolecules, 31, 3639 (1998).

26) Seemork J, Itoh T, Nobukawa S, Yamaguchgi M, Nihon Reoroji Gakkaishi, 44, 23 (2016).

27) Fan B, Wiwattananukul R, Yamaguchi M, Eur Polym J, 96, 295 (2017).

28) Doan VA, Nobukawa S, Yamaguchi M, Compos Part B, 43, 1218 (2012).

29) Yamaguchi M, Hachiya $Y$, Yoon H, Wiwattananukul R, Nobukawa S, J Mat Test Res Assoc Japan, 60, 140 (2015). 